
Instituto Politécnico Nacional

Centro Interdisciplinario de Investigaciones y Estudios Sobre

\section{MÉXICO EN EL ANÁLISIS DE LA ÉTICA EMPRESARIAL NORTEAMERICANA}

Jorge Alejandro Silva-Rodríguez de San Miguel 


\section{3 ciencias}

Editorial Área de Innovación y Desarrollo, S.L.

Quedan todos los derechos reservados. Esta publicación no puede ser reproducida, distribuida, comunicada públicamente o utilizada, total o parcialmente, sin previa autorización.

(C) del texto: el autor

ÁREA DE INNOVACIÓN Y DESARROLLO, S.L.

C/ Els Alzamora, 17 - 03802 - ALCOY (ALICANTE) info@3ciencias.com

Primera edición: abril 2017

ISBN: 978-84-946684-8-7

DOI: http://dx.doi.org/10.17993/EcoOrgyCso.2017.20 


\section{Acerca del autor}

Es Doctor en Ciencias Administrativas por la Escuela Superior de Comercio y Administración Unidad Santo Tomás (ESCA-STO. TOMÁS), Maestro en Administración y Licenciado en Administración Industrial por la Unidad Profesional Interdisciplinaria de Ingeniería y Ciencias Sociales y Administrativas (UPIICSA). Toda su formación la tuvo en el Instituto Politécnico Nacional (IPN).

Su producción científica incluye artículos científicos publicados en revistas indexadas nacionales e internacionales y participaciones en congresos nacionales e internacionales. También cuenta con diversos reconocimientos y distinciones, destacando a nivel doctorado en la rama de las Ciencias Sociales y Administrativas del IPN, la Presea Lázaro Cárdenas, el premio a la mejor tesis de doctorado y el premio al mejor desempeño. Además, es miembro del Sistema Nacional de Investigadores de México.

En el ámbito laboral colaboró en el diseño de un programa de Doctorado en Ciencias de la Administración en la ESCA-STO. TOMÁS. Actualmente, se desempeña como docente en el Centro Interdisciplinario de Investigaciones y Estudios sobre Medio Ambiente y Desarrollo (CIIEMAD) del IPN.

En su carrera académica ha impartido cátedra a nivel maestría y doctorado y ha participado en diferentes proyectos de investigación. Su principal campo de trabajo son las Ciencias Administrativas: Administración Pública y Administración de Empresas. 



\section{Índice}

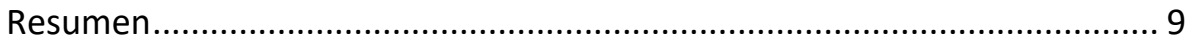

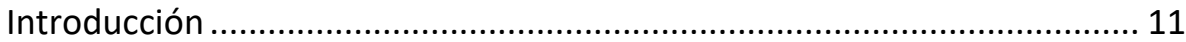

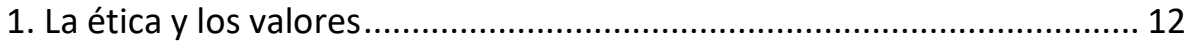

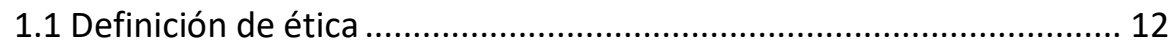

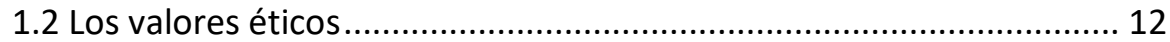

1.3 La ética en los negocios ................................................................. 13

2. La inclusión y exclusión de México en los análisis de la ética empresarial norteamericana y latinoamericana ....................................................... 17

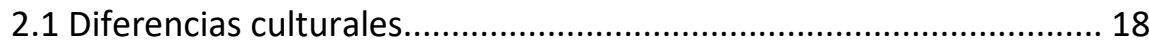

2.1.1 Origen y consecuencias del sentimiento de inferioridad mexicano 20

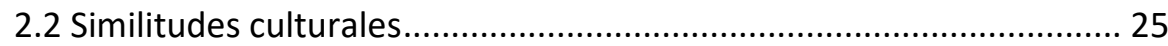

2.3 La ética empresarial en América del Norte y México desde el TLCAN 25

2.4 Cuestiones éticas existentes en México …………………………..... 29

2.5 La perspectiva internacional - el efecto de la globalización y la liberalización del comercio sobre la ética empresarial........................... 32

3. La educación y formación en ética empresarial....................................... 37

3.1 Brechas en la literatura existente y recomendaciones para investigación adicional......................................................................... 38

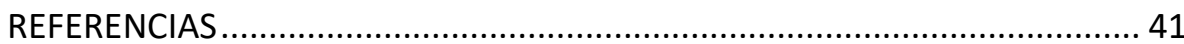





\section{Resumen}

El propósito de este libro es revisar críticamente la literatura sobre la ética empresarial en México, el estudio y la enseñanza de la ética en México y el estado actual de la ética en las relaciones comerciales norteamericanas. Esto libro cubre una parte sustancial de la literatura sobre el tema; para ello se ha incluido el trabajo de los autores más relevantes.

Actualmente, se requiere una revisión de este fenómeno a profundidad debido a que en México uno de los principales problemas que se tienen es el del comportamiento no ético manifestado en corrupción. Además, este tema surgió como un punto de interés en un contexto empresarial y académico hace aproximadamente dos décadas.

La investigación sobre la ética empresarial en México viene a reforzar la comprensión de este fenómeno para plantear sugerencias que influyan en investigaciones futuras que coadyuven en la mejora y ampliación del cuerpo de investigación sobre este fenómeno.

Palabras clave: empresa, ética, cultura, globalización, México, negocios, Norteamérica, TLCAN. 


\section{Introducción}

Este libro sintetiza la investigación sobre ética empresarial en México. Para su conformación, se consultó, de forma amplia, la literatura especializada en el tema tratado como capítulos de libro y documentos, tanto corporativos como oficiales, publicados desde los años setenta.

En este sentido, se identifican los puntos de vista de los académicos en ética empresarial y sus tendencias, reuniendo sus ideas sobre el campo en México en un solo documento. Actualmente, es complicado encontrar en la literatura el abordaje que se le da al tema, como se hace en el presente libro.

Es posible separar la ética empresarial en México en dos grandes categorías: antes de 1994 y después de 1994. Este periodo de tiempo es seleccionado como divisor porque fue en enero de este año en el que el Tratado de Libre Comercio de América del Norte (en adelante el TLCAN) - acuerdo negociado entre los gobiernos de Canadá, Estados Unidos (EE.UU.) y México (Caulfield, 2010) - entró en vigor.

La ética empresarial en México rara vez se trata como un tema de investigación independiente; en cambio, se incorpora a la literatura sobre la ética empresarial norteamericana y latinoamericana o se trata de literatura que discute la responsabilidad social corporativa y el desarrollo sostenible. Sin embargo, incluso en relación con estos dos últimos conceptos, rara vez se maneja como una cuestión de investigación independiente.

La revisión de la literatura sobre el tema sigue el desarrollo de la cobertura de la ética empresarial en México, antes y después del TLCAN y evalúa cómo el enfoque en la ética empresarial ha cambiado desde que México se vio obligado a asegurar que sus prácticas comerciales fueran consistentes con las de sus pares norteamericanos. Además, evalúa el estado actual de la ética empresarial en México en comparación con EE.UU., Canadá y otras naciones del mundo, considera qué factores han cambiado la ética empresarial en México, identifica brechas en la literatura existente y sugiriere direcciones futuras para la continuación de la investigación sobre la ética empresarial. 


\section{La ética y los valores}

\subsection{Definición de ética}

La palabra ética se deriva del latín ethikos, que proviene de ethos que significa "costumbre" o "hábito", por lo que se refiere al estudio o disciplina interesada por los juicios de valor sobre acciones consideradas correctas o incorrectas (Vizcarra, 2004).

La ética es la disciplina filosófica teórico-práctica normativa que tiene por objeto el análisis, la fundamentación de los actos humanos en cuanto a su obrar consciente y libre, así como su regulación. Es normativa sólo en cuanto al concepto de conciencia debido a que no determina lo que es, sino lo que debe ser (Vizcarra, 2004).

De igual forma, es el estudio del comportamiento de los seres humanos (Gran enciclopedia interactiva del saber, 2002).

También es una disciplina que reúne las características de una ciencia porque elabora hipótesis y teorías sobre la moral, analiza conceptos y da a conocer categorías de acuerdo a la experiencia moral (Vizcarra, 2004).

\subsection{Los valores éticos}

Los valores están ligados con la ética, forman parte de la vida y pueden ser de varios tipos: económicos, espirituales, religiosos, intelectuales, cognoscitivos, estéticos, morales, etc. Éstos están por encima de las necesidades inmediatas de un estado de animalidad, por lo que el ser humano es la fuente del valor y de la ética (Campos, 2013).

Estos valores son los medios adecuados para que el ser humano logre sus finalidades. Así, de acuerdo con Salvador García (1997) se diferencian dos tipos de valores: finales (objetivos existenciales) e instrumentales (medios operativos para alcanzar los valores finales) (ver tablas 1 y 2 ). 


\begin{tabular}{|c|c|}
\hline Valores personales & Valores ético-sociales \\
\hline $\begin{array}{l}\text { ¿Qué es para usted lo más } \\
\text { importante en la vida? }\end{array}$ & ¿Qué quiere usted para el mundo? \\
\hline $\begin{array}{l}\text { Vivir, felicidad, salud, familia, éxito, } \\
\text { realización personal, prestigio, } \\
\text { estatus, bienestar material, } \\
\text { sabiduría, amistad, trabajo, respeto, } \\
\text { amor, etc. }\end{array}$ & $\begin{array}{l}\text { Paz, supervivencia ecológica del } \\
\text { planeta, justicia social, etc. }\end{array}$ \\
\hline
\end{tabular}

Fuente: elaboración propia.

Tabla 2: Valores instrumentales

\begin{tabular}{l|l}
\multicolumn{1}{c}{ Valores ético-morales } & \multicolumn{1}{c}{ Valores de competencia } \\
$\begin{array}{l}\text { ¿Qué valores cree que debe tener } \\
\text { con quienes le rodean? }\end{array}$ & $\begin{array}{l}\text { ¿Qué cree que hay que tener para } \\
\text { poder competir en la vida? }\end{array}$ \\
$\begin{array}{l}\text { Honestidad, educación, sinceridad, } \\
\text { responsabilidad, lealtad, solidaridad, } \\
\text { confianza, respeto de los derechos } \\
\text { humanos, etc. }\end{array}$ & $\begin{array}{l}\text { Cultura, dinero, imaginación, } \\
\text { inteligencia, belleza, iniciativa, } \\
\text { pensamiento positivo, constancia, } \\
\text { flexibilidad, } \\
\text { vitalidad, simpatía, capacidad de } \\
\text { trabajo en equipo, coraje, salud, } \\
\text { etc. }\end{array}$ \\
\hline
\end{tabular}

Fuente: elaboración propia.

\subsection{La ética en los negocios}

Una de las vertientes según las cuales la filosofía contemporánea dirige el estudio de la ética es la ética aplicada, la cual visualiza la realidad controversial ubicándose en los diversos campos en los que el hombre se relaciona y adopta el nombre de la realidad en la cual está inmerso. Un ejemplo es la ética empresarial, la cual consiste en el descubrimiento y la aplicación de los valores y normas compartidos por una sociedad pluralista al ámbito peculiar de la empresa (Cortina, 1996).

Por lo anterior, es importante para los integrantes de las organizaciones aprender de la ética empresarial el modo de actuación que el tiempo exige a las organizaciones que quieren sobrevivir, crecer y superarse (Cortina, 1996). 
Cortina (1996) menciona que la ética empresarial debe contar con seis características fundamentales:

- Un sistema de valores que afloran mediante una cultura corporativa.

- Una redefinición a partir de las finalidades de la empresa y, por ende, desde los valores que las identifican.

- Tener un sistema abierto que permita la construcción de una cultura empresarial.

- Rentabilidad para reducir costos, posibilitar la identificación corporativa y la motivación eficiente.

- Cultura empresarial diferenciadora.

- Claridad en la internalización del rol del directivo, identificado con la empresa y con capacidad para integrar al personal.

Conceptualizar y aplicar estos elementos permite fortalecer el comportamiento ético, como lo menciona Guédez (2001): la clave del éxito gerencial está dada por la capacidad de combinar lo que se puede hacer (factor conocimiento) con lo que se quiere hacer (factor emocional) y con lo que se debe hacer (factor ético).

Por otra parte, en la Universidad Nacional de Colombia, sede Manizales, se llevó a cabo, entre 1997 y 2005, una línea de investigación en ética gerencial, cuyo objetivo fue encontrar los comportamientos éticos que los empleados más valoran de sus gerentes, para proveer evidencias de personas con experiencia laboral acerca de los que hacen los gerentes éticos (Rodríguez Córdoba, 2006). Los resultados se muestran en la tabla 3.

Tabla 3: Los 20 comportamientos éticos más valorados por los empleados

\section{Valores ético-morales}

No aceptan la corrupción (honestidad)

Respetan a sus empleados (respeto y tolerancia)

No roban a la empresa (comportamiento hacia la empresa)

No cometen atropellos contra la dignidad humana de sus trabajadores (respeto y tolerancia)

Sancionan ejemplarmente la deshonestidad (honestidad) 
No incumplen acuerdos (responsabilidad, cooperación y amor)

Negocian de forma transparente y honesta (honestidad)

Aceptan la responsabilidad por sus acciones (responsabilidad, cooperación y amor)

No obligan a sus empleados a cometer acciones que vayan en contra de la ley (uso del poder)

Apoyan con sus acciones las campañas anticorrupción (honestidad)

No usan su poder para imponer relaciones no deseadas por los empleados (uso del poder)

No extorsionan a otros (honestidad)

Cuidan que los recursos de la empresa sean bien utilizados (comportamiento hacia la empresa)

No cometen acoso sexual contra sus empleados (uso del poder)

No maquillan los informes financieros para sacar dinero o beneficio propio (comportamiento hacia la empresa)

Desempeñan su trabajo de manera honesta y responsable (honestidad)

Cumplen con las normas que rige el código ético de su empresa o profesión (comportamiento hacia la empresa)

Practican y proyectan valores como la honestidad, la transparencia y la tolerancia (honestidad)

Actúan con justicia y equidad en la crisis y en la bonanza (justicia y equidad)

No les hablan mal a los clientes de la competencia (relaciones con clientes, competencia y proveedores)

Fuente: elaboración propia. 


\section{La inclusión y exclusión de México en los análisis de la ética empresarial norteamericana y} latinoamericana

Las implicaciones éticas de las decisiones empresariales en América del Norte se han investigado detenidamente desde los años setenta. La ética empresarial es moldeada por muchas fuerzas como las circunstancias externas de los mercados competitivos en los que opera una empresa, las características de éstos y los rasgos de los líderes (Trevino, Butterfield, \& McCabe, 1995; Tsakilis \& Frizsche, 1989; Logsdon \& Corzine, 1999). Académicos como Trevino et al., (1995) y Weber (1990) parecen haber estado preocupados principalmente por las disparidades en la toma de decisiones éticas para las personas de una organización y las disparidades en el desarrollo de políticas y procesos éticamente sólidos dentro de las empresas.

La mayor parte de la investigación sobre la ética empresarial, en América del Norte, se ha centrado principalmente en los líderes y las organizaciones estadounidenses. Antes de 1994, importantes catálogos de ética empresarial en América del Norte fueron recopilados; los más notables fueron los de McMahon (1975) y Jones y Bennet (1986), los cuales ofrecían valiosos conocimientos relativos a la educación general en ética empresarial en un contexto académico, además de literatura de ética empresarial de los años 70 y 80 . Sin embargo, estas y otras obras importantes no se han incorporado a México para su análisis. De hecho, es perceptible que la mayoría de las obras importantes antes de 1994 no incluyeran a México en taxonomías norteamericanas sobre ética empresarial, independientemente de que la ubicación geográfica del país se ubique en el continente norteamericano.

En general, debido a que el español es la lengua predominante que se habla en México, y dado que el país tiene una cultura mayoritariamente católica, en muchos análisis de la ética empresarial en México la nación se agrupa a menudo junto con otros países latinoamericanos, incluyendo, pero no limitándose a Costa Rica, El Salvador, Argentina, Brasil, Chile, Colombia, Ecuador, Uruguay, Venezuela y países de la región del Caribe (Rossouw, 2011). La ética empresarial de México no había recibido mucho interés antes de 1994, pero cuando se cubría generalmente se trataba a partir de artículos sobre ética empresarial en América Latina. 


\subsection{Diferencias culturales}

Las personas de cualquier país basan sus decisiones en las preferencias personales, pero estas preferencias se basan en el entorno externo; opiniones, valores y estándares de conducta se desarrollan en relación a la cultura de ese entorno (Hood \& Koberg, 1994). La cultura mexicana, la latinoamericana, la estadounidense y la anglosajona varían enormemente en varios aspectos (Hood \& Logsdon, 2002).

La ética empresarial en México siempre ha sido posible gracias a la antigua convención tradicional del credo católico romano y a la predilección cultural por las relaciones familiares (Petrick, Cragg, \& Sanudo, 2011). Tal predilección cultural implica una fuerte inclinación por las relaciones interpersonales, incluyendo mantener las estimaciones de los demás en alta estima, un alto grado de aquiescencia, respetando los deseos y las creencias de los demás y viendo la desaprobación negativamente (Hood \& Logsdon, 2002). Los individuos son responsables de su propia toma de decisiones, pero se guía por los intereses de la familia (Morrison \& Conaway, 2006). Además, el negocio, generalmente, sólo se lleva a cabo con personas conocidas, y esta familiaridad se considera más importante que la experiencia, el conocimiento y la habilidad de una persona (Morrison \& Conaway, 2006). Sin embargo, la gente en EE.UU. y Canadá sostiene en alto grado la realización de tareas (Triandis, 1996) y la rivalidad (Stewart \& Bennett, 1991). Por lo tanto, los mexicanos suelen ser más colectivistas, concentrando su atención y comportamiento en los intereses, las creencias, los objetivos y las opiniones de otros en lugar de los suyos; mientras que los estadounidenses y canadienses suelen ser más interesados en sí mismos, centrándose en sus propias creencias, objetivos y opiniones (Triandis, 1996).

La palabra "ética" suele invocar una respuesta inquietante y a menudo plana cuando se utiliza en el contexto de relaciones interculturales entre México y EE.UU. en particular (Olivas-Luján, 2016). La percepción mexicana de EE.UU. es mixta. La larga y predominantemente desamparada relación de México con EE.UU. hace que muchos mexicanos se muestren cautelosos en sus negocios con los estadounidenses y con cualquier persona de cualquier nación industrializada en general (Morrison \& Conaway, 2006). Muchos mexicanos creen que los estadounidenses -que a menudo son más avaros y autoindulgentes- han permitido que su buena fortuna los consuma (OlivasLuján, 2016). Además, tienden a culpar a los estadounidenses por la agresión generalizada a través de México por una inclinación general hacia las sustancias ilegales y los productos falsificados. El crimen organizado que se produce para proveer a los estadounidenses de varios artículos ilegales incluyendo sustancias ilegales, como la cocaína y productos falsificados, 
como ropa y tecnología- a menudo involucra brutalidad y derramamiento de sangre (Olivas-Luján, 2016). Sin embargo, otros mexicanos -que elogian a los estadounidenses por su capacidad de gestión y tecnología- desean la misma vida que muchos estadounidenses (Olivas-Luján, 2016).

La investigación de Hofstede (1980) señaló varios aspectos de la cultura que repercuten en la conducta empresarial $y$, en consecuencia, en la ética empresarial en todos los países de América del Norte, incluyendo México: la evitación de la incertidumbre; distancia de poder; individualismo versus colectivismo y masculinidad versus feminidad.

En relación con México, la investigación identificó varios factores: en términos de evitación de la incertidumbre, que era promedio, había un alto respeto por la claridad, un requisito para la regulación oficial y la admiración de la certeza. Por lo tanto, las empresas mexicanas adoptan un enfoque más específico de la ética empresarial (Sower, Abshire, \& Shankman, 1997). En términos de distancia de poder, que era alta, había una tolerancia para un poder y un liderazgo desequilibrados, absolutos y no democráticos. Por lo tanto, los trabajadores mexicanos son menos propensos a cuestionar la decisión de los líderes incluso si pueden tener consecuencias éticas (Hood \& Logsdon, 2002). En términos de individualismo versus colectivismo, hubo un alto grado de colectivismo, un enfoque en relaciones sociales cercanas, evitando la vergüenza y la protección de los empleados por el empleador.

Los mexicanos son más propensos a percibir grupos sociales estrechos (Lawrence \& Yeh, 1994), la protección de esos grupos (Davis, 1969) y la lealtad a esos grupos (Riding, 2007). Tal enfoque de favoritismo no es económicamente beneficioso para las organizaciones a largo plazo, resulta en un ambiente de trabajo caracterizado por la desigualdad y significa que los empleados son menos propensos a ser conscientes de sus derechos y responsabilidades, cuando se han infringido (Sower et al., 1997).

En términos de masculinidad versus feminidad, la masculinidad es alta y se concentra en el logro, la confianza, los estereotipos de género y la creencia de que las mujeres son inferiores a los hombres. Por eso, en México, la igualdad de remuneración entre mujeres y hombres, las normas de acoso sexual y la distribución equitativa del trabajo son menos comunes (Hood \& Logsdon, 2002).

La importante investigación de Hofstede (1980) señaló que en términos de actitudes hacia el trabajo las personas lo ven sólo como una forma de ganarse la vida, como algo que no les gusta pero que deben hacer y como algo que prefieren menos a actividades recreativas. Esto significa que es probable que los trabajadores mexicanos se dediquen a trabajar menos, y que la conducta 
ética - como evitar estar ausente y perder el tiempo en el reloj - es menos probable, al igual que la existencia de mecanismos para manejar cualquier conducta no ética (Graves, 1997). Por el contrario, Olivas-Luján (2016) encontró que la mayoría de los mexicanos que trabajan en los EE.UU. tienen una fuerte ética de trabajo; a menudo aceptan roles muy desafiantes que requieren un rendimiento impecable y ofrecen un mal pago. De hecho, esta percepción norteamericana de las actitudes mexicanas hacia el trabajo ha inspirado a varias empresas estadounidenses -actualmente que operan en la industria automotriz y otras industrias manufactureras- a cambiar sus actividades comerciales a México, donde creen que pueden lograr una mejor producción a niveles más bajos (Olivas-Luján, 2016).

En términos de resolución de problemas, las personas son guiadas por estados de ánimo, sentimientos, actitudes e instintos, más que por lógica, y adoptan un enfoque autónomo para resolver problemas. La consecuencia de este enfoque a la resolución de problemas es que la existencia de políticas éticas -como códigos de conducta- no son comunes en México (Kras, 1989). Por último, en términos de actitudes hacia los seres humanos, la gente cree que ellos se caracterizan por la virtud y la inmoralidad. Esto tiene connotaciones negativas de confianza en las empresas mexicanas y puede perjudicar el impacto en lo que los empleados mexicanos creen que es un comportamiento decente y honorable. Si existe consenso de que las personas son capaces de ser simultáneamente virtuosas e inmorales, entonces es más probable la normalización y la tolerancia del comportamiento no ético, aunque no sea aceptado (Triandis, 1982).

\subsubsection{Origen y consecuencias del sentimiento de inferioridad mexicano}

Retomando la investigación de Silva (2010), es imperioso comprender el sentimiento de inferioridad de la cultura mexicana para conocer el origen del porqué de su comportamiento y su rol en la ética. Por lo anterior, la inferioridad, de acuerdo con Adler (1999), es algo que se vislumbra al momento de nacer $y$, por ello, otras personas deben cuidar de los recién nacidos. El patrón de vida de los niños no se puede entender sin referencia a las personas que los cuidan y, de esta forma, compensan la debilidad de éstos. Cabe destacar que la debilidad de los niños también se puede aplicar a otro tipo de personas porque ellos también viven en comunidades.

Todas las personas en alguna etapa de su vida se sienten incapaces de afrontar algunas situaciones por sí solos. Es por ello que se forman grupos para vivir como miembros de una comunidad. El hombre, con su deseo de seguridad, no sólo lo impele a preocuparse más de lo que exigen sus 
necesidades. Es por eso que, siendo poderoso, es como adquiere la conciencia de seguridad. Por esta razón, las personas pueden ser arrastradas por el afán de poder, como es el caso de ambicionar muchas cosas, algunas de las cuales no están a su alcance. En el caso en que la desproporción que existe entre lo que se desea y lo que se puede hacer sea muy grande, inevitablemente casi cualquier intento desembocará en el fracaso. Acto seguido, el individuo pensará en su incapacidad y, desde ese momento, desconfiará de sí mismo (Ramos, 2004).

Las personas que adquieren el sentimiento de inferioridad tienen actitudes que tienden a darse una superioridad que para las demás personas no existe (Ramos, 2004). Donde hay sentimiento de inferioridad, surge una ambición desmedida de poder. Éste es un paradigma en el cual todo es visto bajo la perspectiva de lo superior y lo inferior. La discordia que esto genera trae como consecuencia el rencor, el odio, el resentimiento, la venganza, el aislamiento, la misantropía, la neurosis, etc. (Ramos, 2004).

La obsesión de sí mismo implica el desprecio a la vida de las demás personas (Ramos, 2004). De acuerdo con Ramos (2004), si una persona vive su vida obsesionado con el sentimiento de ser superior para dominar a los demás, sin objeto alguno, sólo por llenar su vacío, entonces siempre estará viviendo de manera inquieta y a la defensiva. Ramos (2009) menciona que ciertos defectos que tienen los mexicanos hacen referencia a una causa inconsciente: el sentimiento de inferioridad. Este sentimiento no solamente se da en los mexicanos, se puede presentar en todos los hombres, cualesquiera sean sus características. Sin embargo, en México, ocupa proporciones de una deficiencia colectiva. Este sentimiento no siempre se manifiesta en la conciencia del individuo, sino que algunas veces, éste sólo actúa de acuerdo a sus impulsos, sin saber realmente la causa de por qué lo hace. Lo que suele ser consciente son las reacciones que involuntariamente nacen para compensar aquel sentimiento, y que, al repetirlos constantemente, van conformando el carácter individual.

La problemática causada por el sentimiento de inferioridad se incrementa en el momento en que el mexicano no sólo escucha aquellas afirmaciones, sino que, muy en el fondo, también las cree y las reafirma en su quehacer cotidiano. El psicoanálisis del mexicano permite descubrir fuerzas oscuras que, disfrazadas de aspiraciones elevadas, en realidad pretenden un rebajamiento de los individuos. Algunas veces se exaltan valores auténticos, otras veces se imita lo extranjero o bien se rechazan valores (Ramos, 2004).

Ramos (2009) considera que el sentimiento de inferioridad debe ser buscado en el pasaje histórico que va de la Conquista a la Colonización, debido a que uno de los primeros problemas con los que se enfrenta México es con el de 
ser una nación conquistada económica, política y, sobre todo, culturalmente. Sus problemas sociales comienzan en las dinámicas culturales que se generaron en el proceso de la Conquista y que continuaron hasta la Colonia. Sin embargo, donde se manifiesta, es en la Independencia, ya que en esta etapa el mexicano tiene que buscar una identidad propia. Riding (2007) indica que a más de 460 años de la Conquista los mexicanos aún no han asimilado el triunfo de Cortés ni la derrota de Cuauhtémoc. Además, este autor señala que la Conquista fue la que permitió a los colonizadores españoles infundir en los indígenas un sentimiento de inferioridad étnica. Es por ello que existe un menosprecio por los indígenas y un reconocimiento hacia la raza blanca. De esta forma, el mexicano entra en un mundo de fantasía o de adopción de máscaras.

Paz (2010) señala que es extraordinario que hasta ahora continúen los efectos, aunque ya hayan desaparecido las causas. Cabe destacar que los autores no aseguran que el mexicano es inferior, sino que éste se siente inferior (Ramos, 2009). En esta señalización no se pretende incluir a todos los mexicanos, pues quizá existan otros factores individuales del carácter que impidan este sentimiento y cuyo mecanismo debe ser explicado con otros principios científicos (Ramos, 2009).

Otro factor característico de la cultura mexicana es el de la pasión que, de acuerdo con Ramos (2009) es la nota que da el tono a la vida de México. Esto no solamente se lleva a cabo en terrenos políticos, sino a un hecho cualquiera que despierte el interés de las masas. Por ello, tanto una discusión científica, como una controversia artística, nunca transcurren de manera serena, sino que siempre se manifiesta la pasión. Esto obliga a que las personas Ilamen la atención sobre lo que hacen o dicen, por ejemplo: pueden alzar la voz, exagerar los gestos, violentar las expresiones para impresionar al auditorio, etc., y todo esto se puede entender como efectos de la causa que es el sentimiento de inferioridad (Adler, 1999).

Ramos (2009) dice que cuando la razón trata de explicar los procesos que motivan a actuar pasionalmente los encuentra absurdos y carentes de toda lógica. No obstante, la pasión no la ve como un medio, sino como un fin: le parece condenable la pasión cuando constituye un fin en sí mismo, no cuando representa un medio para llegar a un fin que se encuentra fuera de la órbita de aquélla. Este mismo autor comenta que la pasión se propone, inconscientemente, la afirmación del yo individual, haciéndolo prevalecer a toda costa. Además, agrega que hay una pasión introvertida y otra extrovertida, y que un grupo numeroso de mexicanos corresponde a la descripción de una función psíquica inconsciente, y alguna actividad consciente es extrovertida por un mecanismo de compensación. Es decir, es 
introvertida por el lado de su pasión y extrovertida por el lado de la conciencia de sus máscaras.

La pasión orientada hacia el interior de una persona y no hacia afuera representa para la vida social una persona de una fuerza negativa. Ramos (2009) diferencia a una persona que lleva su alma al descubierto, sin que nada esconda en sus más íntimos resortes, por el nombre de "pelado". Éste ostenta cínicamente ciertos impulsos elementales que otras personas hacen el intento de disimular. Este autor señala que el pelado en la jerarquía económica es menos que un proletario y, en la jerarquía intelectual, es un primitivo. La vida de estas personas ha sido hostil por todos lados, y su actitud ante ella es de resentimiento. Asimismo, clasifica al pelado en el grupo de los introvertidos, debido a que ocultan sus verdaderos sentimientos. El pelado es de naturaleza explosiva, cuyo trato es peligroso porque al más ligero provocamiento estalla. Las consecuencias de su estallido se ven reflejadas en su lenguaje verbal y no verbal, y tienen como tema la afirmación de sí mismo en un lenguaje grosero y agresivo. Menciona que el pelado ha creado un dialecto propio cuyo léxico abunda en palabras de uso corriente a las que da un sentido nuevo.

Paz (2010) indica que en el lenguaje del mexicano hay un grupo de palabras sin contenido claro: palabras que sólo se pronuncian en voz alta cuando no se pertenece uno mismo. Ramos (2009) señala que el pelado es un individuo que se hace creer que es más fuerte y decidido. Dichas reacciones son un desquite ficticio de su situación real en su vida diaria. Además, busca la riña para elevar su ser deprimido. Necesita un punto de apoyo para recobrar la fe en sí mismo, pero como está desprovisto de todo valor real, tiene que suplirlo con uno ficticio. El lenguaje del pelado es abundante en alusiones sexuales. En sus discusiones verbales atribuye al oponente una femineidad imaginaria para que, de esta manera, el elemento masculino que es él, agravie al elemento femenino, y el pelado afirme su superioridad contra el oponente. El pelado también asocia su concepto de hombría con el de nacionalidad, lo cual se ve claramente con el futbol.

Ramos (2009) también diferencia al burgués mexicano del pelado. Explica que, en el fondo, el mexicano burgués no difiere mucho del mexicano proletario; en este último, el sentimiento de menor mérito se halla exaltado por la concurrencia de los siguientes factores: la nacionalidad y la posición social. El burgués, a diferencia del pelado, se expresa con una cortesía a menudo extremada. Pero todo mexicano de clase cultivada puede conseguir, cuando un momento de ira le hace perder el dominio de sí mismo, el tono y el lenguaje del pelado. 
Este autor añade que la diferencia psíquica que separa a la clase elevada de mexicanos de la clase inferior radica en que la clase elevada disimula de modo completo sus sentimientos de menor valía; a diferencia del pelado que exhibe con claridad sinvergüenza el componente de su psicología. Menciona que el mexicano burgués posee más dotes y recursos intelectuales que el proletario para llevar a cabo de una mejor forma la simulación de su sentimiento de inferioridad oculto. Esto es semejante a decir que el yo ficticio construido por cada individuo es una obra que se asemeja a la realidad, que es casi imposible distinguirla del yo verdadero. En este tenor, la operación que realiza el mexicano consiste, en su forma más simple, en incorporar la imagen de lo que se quisiera ser a la realidad, y dar esta pretensión por un hecho. Algunas veces, el deseo se circunscribe a soslayar el desprecio o la humillación, y después, en grado ascendente, se encuentra el deseo de predominar entre todos y, finalmente, la voluntad de poderío.

La tarea de construir la propia imagen conforme a un deseo de superioridad requiere una atención y un cuidado constante de uno mismo. Es indispensable que otros hombres crean en esta imagen, para robustecer él su propia fe en ella. Así que su obra de fantasía se realiza con la complicidad social. El mexicano ignora que vive una mentira porque hay fuerzas inconscientes que lo han empujado a ello y, tal vez, si se diera cuenta del engaño, dejaría de vivir así. Cada individuo vive encerrado dentro de sí mismo, tomando una actitud de desconfianza hacia las demás personas. Así como es indiferente a los intereses de la demás gente y sus acciones son individualistas (Ramos 2009).

Otro factor de la cultura mexicana es la pedantería que, de acuerdo con el mismo autor, es aquella máscara que oculta o disimula algo. Es una forma de expresión que es intelectual o pretende serlo. Ésta se encuentra, sobre todo, entre profesores, literatos, artistas, escritores de toda índole, y se manifiesta en el lenguaje verbal o escrito. El lenguaje que utiliza el pedante refleja la finalidad de hacer gala de un talento, de la sabiduría o de la sapiencia. A los pedantes se les ve hablar de ciertos temas, de una manera profunda en medio de una conversación, y aluden a personas famosas o sentencias célebres en lugares y circunstancias fuera de lugar. El pedante aprovecha toda ocasión para exhibir ante grandes o pequeños grupos de personas sus cualidades. El pedante colisiona siempre a los demás, por su carencia de tacto y discreción. Es la persona que en todas las relaciones sociales da un comentario discordante, utilizando para ello un lenguaje y un tono impropio.

El gesto de la pedantería tiene, sin duda, la intención manifiesta de afirmar una superioridad ante los demás, pero de una manera agresiva o con intención de desprecio. El pedante en lugar de obtener el reconocimiento y 
la admiración, no hace más que despertar aversión. Por lo general, los pedantes son violentos autónomos, incapaces de entender los valores ajenos y renuentes a todo esfuerzo en conjunto con la sociedad. Algunas veces, los pedantes logran reunir círculos de admiradores, ingenuos o ignorantes, que se dejan atrapar por sus palabras: al fin y al cabo, el pedante tiene que contentarse con brillar en círculos poco exigentes y modestos, en donde el éxito no constituye ni un mérito ni una satisfacción (Ramos 2009). Ramos dice que la discordancia entre lo que la pedante procura ser y lo que realmente es determina un conflicto resultante del sentimiento de inferioridad. Cuando el pedante tiene el deseo de colocarse en el sitio más alto y no lo logra, la única manera de satisfacer su deseo es con el subterfugio de una ficción. El individuo vive una comedia de superioridad en la que desempeña un papel para engañarse a sí mismo, y de esta manera equilibra su conciencia turbada por el complejo de inferioridad. La clasificación de la pedantería, en los vicios, recae en la categoría de la vanidad (Ramos 2009).

\subsection{Similitudes culturales}

Existen muchas similitudes culturales entre México y otros países de América del Norte, éstos han sido señalados por muchos autores como justificaciones para la inclusión de México en los análisis de ética empresarial norteamericanos. Además, se observan en comparaciones interculturales, después del Tratado de Libre Comercio de América del Norte entre los países. Según Norcia (1997), México y Canadá son comparables de diversas formas: ambos tienen un pasado socialista y una postura reformista y socialista; ambos se inclinan fuertemente hacia la propiedad pública, centrándose en objetivos tanto económicos como sociales. Asimismo, ambos están preocupados por las actividades de las corporaciones globales, especialmente las basadas en los EE.UU. Norcia (1997) señala también que los gobiernos de EE.UU. y México son más federales que el gobierno canadiense, mientras que Alston y Morris (1996) y Norcia (1997) destacan que ambos países son más controladores, otorgando menos valor a la diversidad cultural, especialmente con respecto a las poblaciones aborígenes.

\subsection{La ética empresarial en América del Norte y México desde el TLCAN}

La ética empresarial ha prosperado en América del Norte en general, donde las corporaciones de renombre ofrecen premios de ética empresarial, donde 
los funcionarios de ética son más comunes y más autoritarios, y donde la innovación ética continua es la norma (Petrick et al., 2011). En un contexto académico, varias revistas clave con un enfoque único en la ética empresarial se han popularizado a lo largo de los años, en otros campos han incorporado artículos sobre ética empresarial con más frecuencia y hay un mayor énfasis en este fenómeno en general.

En un contexto de educación empresarial, el enfoque en la ética también se expandió en los EE.UU. y Canadá. Existe un consenso en la comunidad investigadora de que los puntos de referencia para la toma de decisiones éticas son más altos en EE.UU. y Canadá que en México y que los códigos oficiales de ética son mucho más comunes en estos países, especialmente en EE.UU. (Hood \& Logsdon, 2002).

En el período antes de que México entrara en el TLCAN con EE.UU. y Canadá, se estaban haciendo progresos perceptibles, aunque oscuros, académicos y corporativos en relación con la mejora de las cuestiones de conducta ética en México. Estos esfuerzos incluyeron el uso de métodos de enseñanza y entrenamiento discutidos por McMahon (1975), Jones y Bennet (1986), y otros autores más contemporáneos como Petrick et al. (2011), además de autores de reconocidas publicaciones y empresas profesionales. Debido a estos esfuerzos, muchos investigadores comenzaron a enfocarse en la semántica de la ética empresarial en México. Alrededor de ese tiempo, un término en particular - "valores" - ganó popularidad (Blasco, 2008). Debido a los pasos que se están tomando para mejorar la situación, aparentemente no todos los autores vieron la situación en México tan terrible antes de 1994. Por ejemplo, Coutinho de Arruda (1997) argumentó que los siguientes aspectos estaban presentes en cierta medida en el comercio mexicano: las virtudes; integridad; transparencia y equidad. Sin embargo, la opinión de la mayoría era que la situación anterior a 1994 era algo menos positiva que ésta. Las investigaciones percibían la ética empresarial en México de una manera cínica, argumentando la existencia de las siguientes características dominantes del comercio: la corrupción, el soborno, el fraude y la extorsión (Chandan, 2014).

Después de 1994, México enfrentó una abrumadora coerción por parte de EE.UU. y Canadá para alinear su conducta empresarial con la de Norteamérica, lo cual no tuvo ningún impacto negativo en las distinciones culturales del país (Husted, Dozier, McMahon, \& Kattan, 1996). Como resultado, el enfoque en la ética empresarial en México aumentó (OlivasLuján, 2016). En los últimos años, más estudios han incorporado a México en sus análisis de la ética empresarial norteamericana, y ésta, en general, ha surgido como punto focal de investigación, tanto en el ámbito empresarial 
como académico (Dunfee $\&$ Werhane, 1997). Por ejemplo, las consecuencias éticas de la industria maquiladora de México, especialmente, se han convertido en un punto de interés para la comunidad investigadora. Muchos autores han escrito sobre esto, uno de ellos es Raisner (1997), que utilizó la industria como una ilustración para enseñar la ética empresarial. Además, otros estudios también han considerado las implicaciones éticas de la integración en su conjunto. De igual forma, desde el TLCAN, los estudios comparativos interculturales de México, EE.UU. y Canadá -como los de Fritzsche, Huo, Sugai y Tsai (1995), Brody, Coulter and Lin (1999), y Sims y Keenan (1999) - se han vuelto más comunes. La mayoría de estos estudios transculturales no han encontrado disparidades sustanciales entre la toma de decisiones éticas en México y en otros países (Olivas-Luján, 2016).

Aproximadamente hace una década, el foco de la investigación cambió; ahora existe una consideración más amplia de la ética para incorporar la responsabilidad social corporativa y el desarrollo sostenible, lo que significa que la ética se evalúa ahora de diferentes formas. En un sentido amplio, después de 1994, México se centró en la internalización individual y corporativa de la noción de ética (Vargas-Hernández, Leon-Arias, ValdezZepeda, \& Castillo-Giron, 2014). Sin embargo, aunque las mejoras se han hecho académicamente, la ética no prosperó en México en la misma medida que el resto de América del Norte. Si bien se realizaron más investigaciones en relación con la ética empresarial en México, esa investigación no es tan buena o extensiva como la que existe en relación con los EE.UU. y Canadá (Pezoa \& Riumalló, 2009).

Varias de las cuestiones planteadas por los investigadores contemporáneos en relación con la ética empresarial en México son específicas de cada país, pero otras, concretamente aquellas relacionadas con la corrupción, son generalmente aplicables a la mayoría de los países latinoamericanos. La investigación que existe sobre la ética empresarial en México se ocupa de la cuestión de diversas maneras, incluyendo la consideración de la semántica de la ética empresarial, sus desafíos y la posición de la academia en el campo (Coutinho de Arruda, 2009). Si bien las percepciones académicas de la ética empresarial en México eran más escépticas antes de 1994, la situación después de 1994 no mejoró significativamente. La mayoría de los investigadores todavía parecen creer que México aún no ha superado sus desafíos éticos en un contexto empresarial (Pezoa \& Riumalló, 2009).

En los últimos años, varios escándalos empresariales de alto perfil han salido a la luz, que no han pasado por la atención de los medios de comunicación y el público. Un ejemplo de este escándalo fue el de soborno del brazo mexicano de Walmart, Walmex, que involucró a ejecutivos que 
supuestamente pagaban millones de dólares en sobornos para obtener licencias y permisos de zonificación para ubicaciones de tiendas (Ferrell \& Freidrich, 2015). Este comportamiento poco ético de las corporaciones mexicanas ha dejado a la comunidad investigadora sin confianza en la postura ética de México en la conducción de sus actividades comerciales.

Está claro que la percepción de la ética es consistente con estándares pobres o tal percepción se basa en estereotipos pesados (Coutinho de Arruda, 2009; Olivas-Luján, 2016). Un estudio de Volkema (1998) encontró que los estudiantes de negocios que se habían graduado de escuelas mexicanas tenían una diferencia mayor que aquellos que se graduaron de escuelas estadounidenses en su probable empleo. Sin embargo, el estudio encontró que esta diferencia no era como se esperaba; se encontró que los graduados de negocios mexicanos creían que la negociación no ética y las tácticas de toma de decisiones eran menos aceptables que los graduados de negocios estadounidenses. Los hallazgos de este estudio no son consistentes con los del estudio de Hofstede (1980), y muchos otros, que afirman que los mexicanos están más inclinados a emplear comportamientos comerciales poco éticos. Por supuesto, hay muchas formas de desacreditar los resultados del estudio de Volkema (1998), uno de los cuales argumenta que las respuestas de los encuestados pueden no ser confiables como resultado de la conveniencia social, a saber, que los encuestados pueden haber ofrecido respuestas socialmente aceptables. Sin embargo, esto es mera conjetura y no hay manera de probar, por supuesto, que este era el caso. Si esto era una preocupación, entonces seguramente habría sido marcado durante la revisión por pares.

Por otro lado, los resultados de otros estudios han estado uniformemente consonantes con el consenso de que la ética mexicana es cuestionable. Uno de estos es el de Tadepalli, Moreno y Trevion (1999)- que tenía una muestra significativa - encontraron que existían disparidades sustanciales en opiniones acerca de la conducta ética aceptable; los participantes estadounidenses demostraron un mayor grado de toma de decisiones éticas en relación con una variedad de escenarios que son comunes en las transacciones comerciales, incluyendo aceptar recibir vacaciones, regalos y comida o bebida de las personas con las que llevan a cabo negocios. No obstante, las disparidades de extensión eran relativamente insustanciales, y sólo un fenómeno - la conveniencia de exagerar la información a los proveedores para obtener descuentos - variaba ampliamente entre los mexicanos y los estadounidenses; mientras que la variabilidad de otros fenómenos se daba en menor medida. Al referirse a las limitaciones del estudio, los autores señalaron la importancia de tener en cuenta la situación 
económica en ambos países, en lugar de simplemente considerar a una nación para tener un enfoque más éticamente sano (Tadepalli et al., 1999).

Contrariamente a los hallazgos de Volkema (1998), Marta, Heiss y De Lurgio (2008), Tadepalli et al. (1999) encontraron que los participantes estadounidenses tenían valores éticos superiores -que constituían la base de sus percepciones éticas- que los participantes mexicanos, y examinaban las cuestiones en un contexto ético con más frecuencia. Los autores, cuyos hallazgos estaban en consonancia con los de Tadepalli et al. (1999) propusieron que las disparidades se explicaban por las diferencias en las circunstancias económicas de México y EE. UU.; mientras que Tadepalli et al. (1999) encontraron que los gerentes mexicanos son más propensos a aceptar regalos y comidas de aquellos con quienes están haciendo negocios. Es importante recordar que esto no representa necesariamente una ética deficiente. Por el contrario, Morrison y Conaway (2006) señalan que, en muchas culturas de todo el mundo -especialmente las culturas asiática y árabe, pero también, en cierta medida, las culturas europeas- el acto de ofrecer regalos o el curso de las relaciones comerciales no sólo es muy común, sino una parte fundamental de hacer negocios, mientras que no es el caso en otros países - como el Reino Unido (Reino Unido), los EE.UU. y Canadá. Los autores añaden que la mayoría de las secretarias mexicanas realmente esperan regalos de empresarios extranjeros, y a las secretarias que realizan pequeños servicios para cualquier empresario extranjero generalmente se les dan cada vez que esa persona visita su lugar de trabajo.

Al evaluar la postura ética de una nación, es vital que los investigadores tengan en cuenta esta consideración; al hacerlo, se hace evidente que la existencia de tales prácticas puede ser vista no como un comportamiento poco ético sino como un comportamiento tradicional (Coria-Sanchez, 2016). Por lo tanto, tales prácticas simplemente hacen a México -y países con modelos culturales similares- diferente de otros países a nivel mundial, en el que las mismas prácticas son percibidas negativamente. Un estudio realizado por Etheredge y Erdener (1999) encontró que la cultura mexicana era el indicador más significativo del comportamiento ético.

\subsection{Cuestiones éticas existentes en México}

Antes del TLCAN, la información sobre la ética empresarial en México era generalmente negativa. Un enfoque común fue el cuestionable comportamiento ético de las empresas mexicanas, tanto en términos económicos como políticos, que se argumenta que era abundante (Pezoa \& Riumalló, 2009). Además, se discutió que la corrupción, al ser tomada junto 
con un robusto comercio de drogas ilegales, tuvo el efecto de enturbiar las aguas del comercio con temor e inhibición en relación con la práctica ética (Pezoa \& Riumalló, 2009). La prensa popular en EE.UU. y Canadá ha caracterizado a México como una nación con corrupción generalizada y profundamente arraigada; uno en el que el Estado de derecho está seriamente opacado por los cárteles de la droga y en el que la distinción entre intereses y objetivos públicos y privados es ambigua en el mejor de los casos (Olivas-Luján, 2016).

Morrison y Conaway (2006) sostienen que tanto los políticos como la policía son vistos a menudo como deshonestos e insensibles a las necesidades e intereses de otros. Los criminales que no hacen esfuerzos para ocultar sus actividades ilegales - en particular, los involucrados con el narcotráfico - son vistos por el público como heroicos personajes tipo Robin Hood (Grillo, 2011). En comparación con los hallazgos de Hofstede (1980), ¿ha mejorado la situación?, sería razonable pensar que las normas formales en relación con la conducta ética son consideradas menos importantes por las empresas mexicanas, pero no hay una claridad real en esto. Además, sería razonable sugerir que el trato ético de los trabajadores de bajo nivel es mejor en México.

Por otro lado, la investigación de Hofstede (1980) encontró que las compañías mexicanas eran menos propensas a tener reglas formales para una conducta ética. La creciente popularidad de tales reglas en EE.UU. y Canadá ha sido escrita repetidamente, especialmente después de varios escándalos muy publicitados en los años 80 (Berenbeim, 1987, Weaver, Trevino, \& Cochran, 1999). Parece haber una falta de claridad en la literatura con respecto a lo que representa un conjunto de reglas formales (Ferrell \& Freidrich, 2015, Weaver, 1993), pero el desarrollo de declaraciones organizativas inequívocas de criterios éticos dentro de las empresas es evidente en EE.UU. y Canadá (Weaver et al., 1999; Ferrell \& Freidrich, 2015). Sin embargo, sigue siendo relativamente ambiguo, si se puede decir lo mismo de México. Mientras que Hofstede (1980) señaló que las empresas mexicanas tienen moderadamente alta evitación de la incertidumbre, lo que debería hacerlos más propensos a desarrollar normas éticas definidas en un código de ética formal para minimizar la incertidumbre, no está claro en la literatura actual si este es el caso.

Hofstede (1980) también encontró que las empresas mexicanas tienen una distancia de alta potencia, lo que debería indicar una menor probabilidad de tener reglas éticas formales, principalmente porque la toma de decisiones es autocrática y los empleados simplemente siguen las órdenes de sus gerentes. Una vez más, no está claro si este es el caso en la actualidad. 
El tratamiento ético de los trabajadores de bajo nivel se relaciona con el pago de salarios justos, ofreciendo seguridad en el empleo, la creación de un ambiente de trabajo seguro y normas generales sobre el bienestar de los trabajadores (Arnold, Beauchamp, \& Bowie, 2013; Boylan, 2013). Las relaciones de empleo implican un conjunto de derechos y responsabilidades, para todas las partes, que son proporcionados por la ley y difieren entre países. En México, los contratos morales, que también incorporan valores culturales, parecen tener mayores puntos de referencia para la seguridad en el empleo y las correspondientes responsabilidades de permanecer en una empresa (Fernando, 2010).

Con referencia a los hallazgos de Hofstede (1980), sería razonable pensar que las empresas de las naciones más colectivistas -como México- tendrían más probabilidades de tratar a sus trabajadores de una manera ética. Por otra parte, sería sensato considerar que la actitud de los trabajadores mexicanos al trabajo puede tener un impacto en el trato ético de éstos por parte de las empresas. Lee y Lee (2010) y Ferrell, Fraedrich y Ferrell (2006) proponen que cuando los trabajadores tienen una estimación más baja del trabajo los empleadores tienen menos probabilidades de explotar esto en su beneficio. Por ejemplo, Ferrell et al. (2006) sugieren que, debido a que el trabajo no es tenido en alta estima por los trabajadores mexicanos, es improbable que ciertos estándares éticos -como hacer lo que sea necesario para hacer algo bien en el trabajo- se desarrollen.

El soborno de los gerentes públicos para la adquisición de negocios o trato preferencial en México sigue siendo un tema importante (Morris, 2009). Funciona en contra de la naturaleza misma de la ética, ya que tiene en cuenta el oportunismo egocéntrico en mayor medida, que las normas comerciales y legales no discriminatorias para la distribución de negocios y la institución de pautas para llevarlos a cabo (Jennings, 2014; Ferrell \& Freidrich, 2015). A lo largo de los años, EE.UU. y Canadá han desarrollado regulaciones, cuyo objetivo es combatir el soborno de funcionarios gubernamentales (Hood \& Logsdon, 2002). Según Biegelman y Biegelman (2010), Transparency International - una organización que evalúa la frecuencia de sobornos en la mayoría de las naciones - encontró, en su Índice de Percepción de la Corrupción 2011, que México tiene una puntuación de 3 en una escala de 1 a 10; donde las cifras más bajas constituyen una percepción más elevada de la corrupción. Los autores señalan que México fue una de las naciones que se caracteriza por un grado comparativamente más alto de corrupción, situándose en el puesto número 100 de un total de 183 países. La puntuación es la más pobre jamás otorgada a México por Transparencia Internacional (Biegelman \& Biegelman, 2010). Nee (2014) afirma que el $31 \%$ de las empresas mexicanas sobornó a funcionarios para agilizar el papeleo u otros 
procesos administrativos entre 2009 y 2010, lo que representa un aumento del 3\% desde 2006. La evidencia proviene de innumerables casos de sobornos reportados en el país, que incluyen figuras públicas de alto nivel que logran una increíble riqueza en tan sólo unos meses de estar en el cargo público (Olivas-Luján, 2016).

Las empresas estadounidenses son capturadas una y otra vez ofreciendo sobornos a los funcionarios del gobierno y participando en otras actividades corruptas (Ferrell \& Freidrich, 2015). Los escándalos políticos como los discutidos, incluyendo los relacionados con el narcotráfico, actúan como barreras a la expectativa de conducta ética empresarial en la nación (Coutinho de Arruda, 2009; Olivas-Luján, 2016). Sobre la base de las pruebas, es evidente que las empresas mexicanas son más propensas a sobornar a los funcionarios gubernamentales para promover sus intereses comerciales que otros países de América del Norte (Hood \& Logsdon, 2002) como resultado de su moderadamente alta evitación de la incertidumbre, las características colectivistas y la postura sobre la naturaleza humana (Hofstede, 1980).

\subsection{La perspectiva internacional - el efecto de la globalización y la liberalización del comercio sobre la ética empresarial}

La globalización y la liberalización del comercio - y el consiguiente aumento de los negocios internacionales - se citan a lo largo de la literatura como cuestiones que tienen un impacto sustancial en la ética empresarial. Hood y Logsdon (2002), por ejemplo, señalan que las naciones industrializadas han alentado durante mucho tiempo la liberalización del comercio para mejorar la coherencia económica y la posición competitiva. Varios acuerdos y negociaciones comerciales multilaterales entre países han logrado estos objetivos (Villarreal, 2012). El deseo de liberalizar el libre comercio llevó al desarrollo del TLCAN, que no recibió amplio apoyo, ya que muchos expresaron su preocupación por el hecho de que el acuerdo sería problemático de varias formas (Vogel, 1997). La crítica del TLCAN fue principalmente ideológica (Hood \& Logsdon, 2002). Sin embargo, en el centro de la condena se encuentran los temores en relación con los diferentes valores éticos y la consecuente conducta y comportamiento empresarial de los países participantes, que se consideraron potencialmente perjudiciales (Hussain, 2010).

Según Carroll y Buchholtz (2014), se requería una acción drástica e inminente para contrarrestar los efectos negativos. Los autores argumentan que la globalización ha tenido el impacto de forzar vínculos entre las organizaciones 
mexicanas y las de otras partes del mundo con diferentes posturas éticas. Otros autores discuten el impacto de la globalización en la ética en México, y la cuestión parece ser una división. Varias personas caen en el campo de pensamiento de que la ética de las corporaciones que llevan a cabo negocios a nivel mundial son superiores a aquellas -como México, Brasil y Perú- que conducen negocios domésticos solamente (Brenkert \& Beuchamp, 2010; Milovanović, Barac, \& Andjelković, 2009). No obstante, otros que caen en un campo de pensamiento diferente, ven la ética de las corporaciones nacionales de una manera más positiva desde que México ingresó al TLCAN; sostienen que los cambios en la ética empresarial en México, y en América Latina en general, deben ser considerados como sustanciales (Pezoa \& Riumalló, 2009).

Los esfuerzos de algunas empresas mexicanas por realizar negocios tanto a nivel nacional como internacional han obligado a muchas empresas mexicanas a mantenerse a un criterio ético más alto (Milovanović et al., 2009). Por ejemplo, Logsdon y Wood (2005) afirman que la existencia de un código de ética y una sólida postura ética se hizo necesaria para la formación de contratos internacionales para empresas extranjeras con la finalidad de confirmar la posición de las empresas mexicanas con las que estaban haciendo negocios. Hood y Logsdon (2002) añaden que era esencial para mejorar la confianza en la ética empresarial de las empresas mexicanas porque esto tendría un impacto positivo en la facilitación de la negociación de contratos; si las empresas internacionales percibían alguna incompatibilidad ética con las empresas mexicanas, entonces su confianza sería agotada y harían suposiciones de riesgo.

La percepción de que las empresas mexicanas no valoran la conducta ética de la misma manera que las empresas de otros países puede tener un impacto perjudicial en el desarrollo de relaciones legítimas de negocios internacionales e incluso pueden traer negocios a México por razones equivocadas, ya que algunas empresas buscarán beneficiarse de unos estándares éticos más flexibles (Olivas-Luján, 2016). Hood y Logsdon también sugirieron en 2002 que esperaban que el continuo efecto de la globalización fuera el comercio global mejorado. Aguilar, Sisto, Ayala, Chapa y Hidalgo (2014) confirman estas expectativas, argumentando que, en la última década, la globalización ha facilitado el comercio mundial, especialmente en el oeste geográfico. Debido a que el comercio global ha mejorado, el comportamiento corporativo y las posturas éticas de las culturas cruzadas son más importantes que nunca en la comprensión y la habilitación de los resultados empresariales (Hood \& Logsdon, 2002). 
Se han realizado muchas investigaciones sobre puntos de vista éticos y la adopción de normas formales sobre ética en todo el mundo. Como era de esperar, los resultados de cada uno de ellos han variado. Algunas investigaciones han encontrado que los puntos de vista sobre cuestiones éticas se ven sustancialmente afectados por el país y los mercados específicos en los que opera una organización (Schlegelmilch \& Robertson, 1995; Becker \& Fritzsche, 1987). Investigación realizada por Abratt, Nel y Higgs (1992) sugirieron que los líderes en Sudáfrica y Australia creen que la cultura tiene un efecto insignificante, si es que existe, en las actitudes éticas. En su estudio, Langlois y Schmegelmilch (1990) - que señalaron que los valores culturales pueden afectar la probabilidad de que las empresas desarrollen normas éticas oficiales - identificaron diferencias en la utilización y naturaleza de las normas formales sobre ética entre empresas alemanas y estadounidenses. Se ha observado que las empresas en Alemania, entre otros países, tienen estándares más altos de seguridad en el empleo y las correspondientes responsabilidades de seguir con un empleador, mientras que los de otros países -como los EE.UU. y Canadá- han establecido procedimientos por los cuales las empresas pueden rescindir contratos de trabajo sin causa y por la cual los empleados pueden salir sin aviso si lo desean (Hood \& Logsdon, 2002; Fernando, 2010).

Las investigaciones de Jackson y Artola (1997) y Sower et al. (1997) propusieron que no es el país en el que opera una organización, sino el país natal de la organización, que guía las actitudes éticas e influye en los puntos de vista sobre una variedad de escenarios éticos. Hood y Logsdon (2002) afirman que el negocio de la conducta en otros países conduce a una mayor complejidad en la toma de decisiones éticas, principalmente como resultado de disparidades notables entre los valores y comportamientos del país anfitrión. Donaldson (1989) señala que el discurso sobre la ética empresarial internacional se divide en dos grupos de pensamiento: algunos creen que las compañías extranjeras adaptan su punto de vista ético para ser consistentes con el del país en el que operan, lo que significa que es posible que una empresa tenga muchos puntos de vista éticos diferentes en todo el mundo; mientras que otros creen que las compañías toman un enfoque consistente ético en todas las naciones en las que opera. No obstante, ninguno de estos argumentos es totalmente fiable. Hood y Logsdon (2002) sugieren que cuando una empresa alinea su postura ética con la de su país anfitrión, mientras sigue siendo respetuosa con las tradiciones de su país, tiene implicaciones negativas para las tradiciones del país de origen de la compañía. También sugieren que cuando las empresas aplican los estándares éticos de su país de origen en cualquier país de operación -por ejemplo, la existencia de una política única de corrupción- no tienen en cuenta las 
distinciones admisibles que pueden existir entre los diferentes países (Windsor \& Getz, 1999).

Elder y Johnson (1999) examinan el tema en un contexto de género; mientras que algunos países protegen firmemente la igualdad de género mediante la legislación, otros no la valoran. Esto fue encontrado en relación con México por Hofstede (1980). Aunque ambos enfoques tienen valor ético, tampoco es una panacea: lo que es correcto para las prácticas éticas de una empresa será diferente para otra (Donaldson, 1989; Brady, 2012). 


\section{La educación y formación en ética empresarial}

Se discutió antes que la situación en México comenzó a cambiar cuando se hicieron esfuerzos para educar a las organizaciones sobre la ética empresarial (Petrick et al., 2011). El éxito marginal de estos esfuerzos puso de relieve la necesidad desesperada e inminente de mejorar el conocimiento y la comprensión de la ética empresarial mediante cursos de capacitación y otros medios educativos. Dos retos comunes han aparecido una y otra vez en la literatura sobre ética en América Latina: en primer lugar, la creación de valor en relación con la ética para niños y jóvenes adultos; $y$, en segundo lugar, la inclusión de la ética en los planes de estudio de negocios en toda América Latina.

Pezoa y Riumalló (2009) consideran que el enfoque de las instituciones académicas no ha contribuido significativamente a la mejora de la ética empresarial. Este sentimiento es reflejado por muchos otros autores. Raisner (1997) sugiere que la inclusión de la ética empresarial en los currículos mexicanos es más fácil decirlo que hacerlo porque la naturaleza ideológica de la ética a menudo es incompatible con el enfoque de los planes de estudio de las empresas sobre soluciones prácticas. Añade que los esfuerzos para enseñar la ética empresarial a nivel institucional y a nivel nacional han sido indeterminados e inconsecuentes.

Por otro lado, investigación realizada por Christensen, Peirce, Hartman, Hoffman y Carrier (2007) encontró que la ética es ahora un aspecto clave de los planes de estudios de negocios en toda América del Norte, pero que, de las escuelas de negocios más destacadas incluidas, ni siquiera una de ellas estaba en México. Parece que la educación ética no es una prioridad clave en México, donde las corporaciones no confían en el aporte significativo de las instituciones educativas; lo mismo se puede decir de otros países de América Latina (Pezoa \& Riumalló).

Por otra parte, Tsalikis, Seaton y Shepherd (2014) sugieren que las organizaciones mundiales tienen una postura ética más fuerte y no requieren la asistencia de las universidades en este sentido. Por otra parte, proponen que varias organizaciones éticas -como la Asociación Latinoamericana de Ética (Moore, 2010) - han intentado persuadir a los expertos académicos para que creen condiciones obligatorias y voluntarias, elaboren programas de ética empresarial, realicen sesiones de capacitación, ofrezcan servicios de consultoría y escriban sobre el tema para publicaciones académicas o de otro tipo. Los autores sugieren que, al hacerlo, los académicos podrían ayudar a las empresas mexicanas -y aquellas que trabajan para esas empresas- a dar una consideración real y significativa a las cuestiones éticas, lo que permitiría 
a las personas desarrollar una base de conocimiento más fuerte que pueda aplicarse a su propio negocio.

Otros autores han ofrecido sugerencias sobre la forma en que la ética empresarial puede ser enseñada e incluida en los planes de estudios de las escuelas de negocios con éxito, pero está claro que existe un potencial significativo de mejora (Olivas-Luján, 2016).

\subsection{Brechas en la literatura existente y} recomendaciones para investigación adicional

En 2002, Hood y Logsdon sugirieron que una de las áreas clave que requerían más investigación en relación con la ética empresarial era la prevalencia del soborno en México. Sin embargo, desde entonces, se ha vuelto más claro que el soborno, como se discutió, sigue siendo un tema importante para la ética empresarial de la nación y no requiere más investigación empírica. La única investigación necesaria a este respecto sería, por ejemplo, el seguimiento de la última puntuación de México del Î́ndice de Percepción de la Corrupción de Transparencia International.

Es menester una investigación adicional sobre si los criterios de Hofstede (1980) siguen siendo aplicables a las empresas mexicanas, hoy en día, para determinar las respuestas a las siguientes cuestiones: en primer lugar, desde el TLCAN, se ha mejorado la adopción de normas éticas formales, pero es necesario saber si el nivel de trato ético de los trabajadores de bajo nivel en las empresas mexicanas es realmente mejor que en otras partes de América del Norte. Para responder este cuestionamiento, se podría adoptar un enfoque de encuesta: esto implicaría examinar una serie de empresas de tamaño similar que operan en mercados similares para ayudar a identificar lo que cuentan como directrices oficiales de ética (Rezaee, 2009).

De igual forma, es imperioso analizar los rasgos culturales entre México y otros países identificados en la literatura. Para ello, la cuestión podría ser evaluada desde una perspectiva de recursos humanos, teniendo en cuenta las políticas y procesos de las empresas mexicanas (Crane \& Matten, 2016).

La atención académica a la ética empresarial en México sigue siendo relativamente escasa, en general, pero hay una notable falta de teoría en la investigación existente (Randall \& Gibson 2012). La comunidad investigadora podría remediar este problema centrándose en el desarrollo teórico en este campo de estudio (Smith, 1991; Bonoma, 1985). Randall y Gibson (2012) sostienen que esto ha permanecido igual en los últimos años, no sólo en relación con México, sino en general; en un intento por alejarse de la 
investigación exploratoria y descriptiva, es esencial que los académicos trabajen hacia la formulación de marcos teóricos. Los autores añaden que la teoría es una parte vital del proceso de investigación, ya que puede ser utilizado como las bases sobre las cuales los investigadores de ética empresarial pueden hacer pronósticos en relación con la postura ética y la conducta probable en determinadas circunstancias.

En 2002, Hood y Logsdon subrayaron que los investigadores no necesitan ni siquiera desarrollar su propia base teórica porque muchos modelos teóricos siguen sin ser probados. La utilización de casos estudio - que examinan las circunstancias dentro de su propio contexto utilizando una variedad de pruebas para crear una comprensión global del área de investigación (Jennings, 2014, Yin, 1989) - podría ser beneficioso para el desarrollo de una base teórica. Otro enfoque podría ser la examinación de un mayor número de empresas que operan en México y en otros países, como los innumerables exámenes de Walmart en EE.UU. y Walmex en México (Gini, 2005). Este enfoque permitiría a los investigadores manejar varias variables contradictorias, como el tamaño de las empresas y la naturaleza de los mercados en los que operan esas empresas.

Se señaló anteriormente que la ética empresarial en México es un punto de interés relativamente nuevo para las organizaciones y para la comunidad académica. La mayoría de las investigaciones sobre el tema en México -y en América Latina en general- no sólo han sido descriptivas y exploratorias; también se ha centrado en la enseñanza de la ética empresarial y su inclusión en los planes de estudio de las escuelas de negocios, utilizando principalmente casos de estudio. En consecuencia, existe un requisito definitivo e inminente para la investigación sobre la toma de decisiones éticas en las empresas mexicanas.

Muchos estudios que encuentran diferencias entre México y otros países, en términos de toma de decisiones, no toman en cuenta que, a pesar de la participación de México en el TLCAN, el país se encuentra en una etapa diferente de desarrollo económico. Además, muchos estudios no tienen en cuenta las prácticas culturales comunes que se perciben como poco éticas en un país, sino éticas en otro. El hecho de no considerar la diferente etapa de desarrollo económico de México y las diferentes costumbres comerciales hace que las evaluaciones de los estándares éticos de México sean injustas. Por esta razón, existe un valor potencial en el desarrollo de un modelo de evaluación que influya en la etapa de desarrollo económico del país y sus prácticas de negocios consideradas como una parte importante de las relaciones comerciales. La aplicación de tal modelo podría significar que las normas éticas relativas del país no son desproporcionadas con las de otros. 
Se necesita un mayor número de comparaciones interculturales entre México y otros países; mientras que ahora existen grandes comparaciones interculturales entre México, Canadá y EE.UU., existen aún menos entre México y otros países. Muchos beneficios de la investigación intercultural existen, pero, sobre todo, falta añadir profundidad y riqueza al cuerpo de investigación y ofrecer diferentes ideas imposibles de recoger a través de otra investigación menos objetiva (Crane \& Matten, 2016). La realización de estos estudios ayudaría a incrementar la conciencia intercultural.

Como se ha planteado, México difiere muchos de otros países en relación a su cultural: sus ciudadanos tienen una forma muy diferente de hacer las cosas, y es importante que los investigadores sean conscientes de estas diferencias (Ilesanmi, 2009). Esto se vincula con la necesidad de tener en cuenta las costumbres individuales de los mexicanos y su relación -o falta de relación- con los valores éticos. 


\section{REFERENCIAS}

Abratt, R., Nel, D., \& Higgs, N. S. (1992). An examination of the ethical beliefs of managers using selected scenarios in a cross-cultural environment. Journal of Business Ethics, 11(2): 29-35. doi:10.1007/BF00871989.

Adler, A. (1999). Comprender la vida (Paidós, Trad.). España: Paidós. (Trabajo original publicado en 1927).

Aguilar, I., Sisto, N. P., Ayala, E., Chapa, J., \& Hidalgo, B. (2014). Trade flows between the United States and Mexico: NAFTA and the border region. Journal of Urban Research, 10, 44-67.

Alston, J. P., \& Morris, T. M. (1996). Comparing Canadian and American values: new evidence from national surveys. American Review of Canadian Studies, 26(3): 301-315. doi:10.1080/02722019609481189

Arnold, D. G., Beauchamp, T. L., \& Bowie, N. L. (2013). Ethical theory and business. Englewood Cliffs, NJ: Prentice-Hall.

Arruda, M. C. (1997). Business ethics in Latin America. Journal of Business Ethics, 16(14), 1597-1603. doi:10.1023/A:1005823317019.

Coutinho de Arruda, M. C. (2009). Ethics and corporate social responsibility in Latin American small- and medium-sized enterprises. Challenging development. African Journal of Business Ethics, 4(2), 37-47.

Becker, H., \& Fritzsche, D. J. (1987). A Comparison of the Ethical Behavior of American, French and German Languages. Columbia Journal of World Business, 22(4), 87-95.

Berenbeim, R. (1987). Corporate ethics. New York, NY: Conference Board.

Biegelman, M. T., \& Biegelman, D. R. (2010). Foreign Corrupt Practices Act Compliance Guidebook: Protecting Your Organization from Bribery and Corruption. New York, NY: John Wiley and Sons.

Cortina, A. (1996). Ética de la empresa. Claves para una nueva cultura empresarial. España: Trotta.

Gran enciclopedia interactiva del saber (2002). Oaxaca: Programa Educativo Oaxaca.

Pezoa, A., \& Riumalló, H. (2009). Latin America. In Rossouw, D., \& Stuckelberger, C. (Eds.), Global survey of business ethics in teaching, training, and research (pp. 19-90). Geneva: Globethics.net. 
Blasco, M., \& Zolner, M. (2008). Corporate Social Responsibility in Mexico and France: Exploring the Role of Normative Institutions. Business Society, 49(2), 216-251.

Bonoma, T. V. (1985). Case research in marketing: opportunities, problems, and a process. Journal of Marketing Research, 22(2), 199-208.

Boylan, M. (2013). Business ethics. New York, NY: John Wiley and Sons.

Brady, F. N. (2012). Ethical universals in international business. New York, NY: Springer.

Brenkert, G. G., \& Beuchamp, T. L. (2010). The Oxford handbook of business ethics. Oxford, UK: Oxford University Press.

Brody, R. G., Coulter, J. M., \& Lin, S. (1999). The effect of national culture on whistle-blowing perceptions. Teaching Business Ethics, 3(4), 385-400.

Campos, G. E. (2013). Ética y Valores, segunda edición. México: Patria.

Carroll, A. B., \& Buchholtz, A. K. (2014). Business and Society: Ethics, Sustainability, and Stakeholder Management. USA: Cengage Learning.

Caulfield, N. (2010). NAFTA and Labor in North America. Champaign, IL: University of Illinois Press.

Chandan, H. C. (2014). Business Ethics in Latin America and Its Impact on Sustained Economic Growth. En Christiansen, B. (Ed.), Handbook of Research on Economic Growth and Technological Change in Latin America (154-173). New York, NY: Springer.

Coria-Sanchez, C. M. (2016). Mexican business culture in trade books: past and present. En Coria-Sanchez, C. M., \& Hyatt, J. T. (Eds.), Mexican business culture: essays on tradition, ethics, entrepreneurship and commerce, and the state (9-25). Jefferson, NC: McFarland \& Company, Inc, Publishers.

Cortina, A. (1996). Ética de la empresa. Claves para una nueva cultura empresarial. España: Trotta.

Crane, A., \& Matten, D. (2016). Business ethics: managing corporate citizenship and sustainability. Oxford, UK: Oxford University Press.

Christensen, L. J., Peirce, E., Hartman, L. P., Hoffman, W. M., \& Carrier, J. (2007). Ethics, CSR, and sustainability education in the Financial Times top 50 global business schools: Baseline data and future research directions. Journal of Business Ethics, 73(4), 347-368. 
Davis, S. M. (1969). U.S. versus Latin America: business and culture. Harvard Business Review, 47, 88-99.

Donaldson, T. (1989). The ethics of international business. New York, NY: Oxford University Press.

Dunfee, T. W., \& Werhane, P. (1997). Report on Business Ethics in North America. Journal of Business Ethics, 16(14), 1589-1595.

Dunfee, T. W., \& Donaldson, T. (2008). Social Contract Approaches to Business Ethics: Bridging the "Is-Ought" Gap. En Frederick, R. E. (Ed.), A Companion to Business Ethics (38-55). Malden, MA: Blackwell Publishing.

Elder, S., \& Johnson, L. J. (1999). Sex-specific labour market indicators: What they show. International Labour Review, 138(4), 447-464.

Etheredge, J. M., \& Erdener, C. B. (1999). Ethical decision patterns in four countries: contrasting theoretical perspectives. En Enderle, G. (Ed.), International Business Ethics: Challenges and Approaches (51-66). Notre dame, IN: University of Notre Dame Press.

Fernando, A. C. (2010). Business ethics and corporate governance. India: Pearson Education.

Ferrell, O. C., Fraedrich, J., \& Ferrell, L. (2006). Business ethics, $4^{\text {th }}$ ed. Boston, MA: Houghton Mifflin.

Ferrell, O. C., \& Freidrich, J. (2015). Business ethics: ethical decision-making and cases. Boston, MA: Cengage.

Fritzsche, D. J., Huo, Y. P., Sugai, S., \& Tsai, S. D. (1995). Exploring the ethical behavior of managers: a comparative study of four countries. Asia Pacific Journal of Management, 12(2), 37-61.

Gini, A. (2005). Case studies in business ethics. London, UK: Pearson Education.

Graves, R. (1997). "Dear friend" (?): culture and genre in American and Canadian direct marketing letters. Journal of Business Communications, 34(3), 235-252.

Grillo, I. (2011). El Narco: the bloody rise of Mexican drug cartels. London, UK, Bloomsbury.

Guédez, V. (2001). La ética gerencial. Instrumentos estratégicos que facilitan decisiones correctas. Venezuela: Planeta.

Hofstede, G. (1980). Culture's consequences. Beverly Hills, CA, Sage. 
Hood, J. N., \& Koberg, C. S. (1994). Patterns of differential acculturation and assimilation for women in business organizations. Human Relations, 47(2), 159-81.

Hood, J. N., \& Logsdon, J. M. (2002). Business ethics in the NAFTA countries: a cross-cultural comparison. Journal of Business Research, 55(3), 883890.

Hussain, I. (2010). The Impacts of NAFTA on North America: Challenges outside the Box. Basingstoke, UK: Palgrave Macmillan.

Husted, B. W., Dozier, J. B., McMahon, T., \& Kattan, M. W. (1996). The Impact of Cross-National Carriers of Business Ethics on Attitudes about Questionable Practices and Forms of Moral Reasoning. Journal of International Business Studies, 27(2), 391-411.

Ilesanmi, O. O. (2009). What is cross-cultural research? International Journal of Psychological Studies, 1(2), 82-96.

Jackson, T., \& Artola, M. C. (1997). Ethical beliefs and management behaviour: a cross-cultural comparison. Journal of Business Ethics, 16(11), 1163-73.

Jennings, M. M. (2014). Business ethics: case studies and selected readings. Stamford, CT: Cengage learning.

Jones, G. D., \& Bennett, P. (1986). A Bibliography of Business Ethics, 19811985. New York, NY: Edwin Meller Press.

Kras, E. S. (1989). Management in two cultures: bridging the gap between U.S. and Mexican managers. Yarmouth, ME: Intercultural Press.

Langlois, C. C., \& Schlegelmilch, B. B. (1990). Do corporate codes of ethics reflect national character? Evidence from Europe and the United States. Journal of International Business Studies, 21(4), 519-539.

Lawrence, J. J., \& Yeh, R. (1994). The influence of Mexican culture on the use of Japanese manufacturing techniques in Mexico. Management International Review, 34(1), 49-66.

Lee, D. E., \& Lee, E. J. (2010). Human rights and the ethics of globalization. Cambridge, UK: Cambridge University Press.

Logsdon, J. M., \& Corzine, J. B. (1999). The CEO's psychological characteristics and ethical culture. En Rahim, M. A., Golembiewski, R. T., \& Mackenzie, K. D. (Eds.), Current Topics in Management (63-79). Stamford, CT: JAI Press. 
Logsdon, J. M., \& Wood, D. J. (2005). Global business citizenship and voluntary codes of ethical conduct. Journal of Business Ethics, 59(1), 55-67.

Marta, J., Heiss, C. M., \& De Lurgio, S. A. (2008). An exploratory comparison of ethical perceptions of Mexican and US Marketers. Journal of Business Ethics, 82(3), 539-555.

McMahon, T. F. (1975). Report on the Teaching of Socio-Ethical Issues in Collegiate Schools of Business/Public Administration. (Technical report). Charlottesville, VA: Centre for the Study of Applied Ethics at University of Virginia.

Milovanović, G., Barac, N., \& Andjelković, A. (2009). Corporate social responsibility in the globalization era. Economics and Organization Journal, 6(2), 89-104.

Moore, G. (2010). Fairness in international trade. New York, NY: Springer.

Morris, S. D. (2009). Political corruption in Mexico: The impact of democratization. Boulder, CO: Lynne Reiner Publishers.

Morrison, T., \& Conaway, W. A. (2006). Kiss, bow or shake hands: The bestselling guide to doing business in more than 60 countries. Avon, MA: Adams Media.

Nee, P. W. (2014). How to Get Rich Doing Business in Mexico: Mexico Business Guide and Contacts. Boston, MA: The Internationalist Publishing Company.

Norcia, V. D. (1997). Business ethics in Canada: Distinctiveness and directions. Journal of Business Ethics, 16(6), 583-590.

Olivas-Luján, M. R. (2016). Perceptions of Ethical Decision Making in Mexican Business: State of the Literature and an Exploratory Study. En CoriaSánchez, C. M., \& Hyatt, J. T. (Eds.), Mexican business culture: essays on tradition, ethics, entrepreneurship and commerce, and the state (92-106). Jefferson, NC: McFarland \& Company, Inc, Publishers.

Paz, O. (2010). El laberinto de la soledad, Postdata y Vuelta a El laberinto de la soledad. México: Fondo de Cultura Económica.

Petrick, J. A., Cragg, W., \& Sanudo, M. (2011). Business ethics in North America: Trends and challenges. Journal of Business Ethics, 104(1), 5162. 
Raisner, J. A. (1997). Using the "Ethical Environment" Paradigm to Teach Business Ethics: The Case of the Maquiladoras. Journal of Business Ethics, 16(2), 1331-1346.

Ramos, S. (2009). El perfil del hombre y la cultura en México. México: Planeta Mexicana.

Randall, D. M., \& Gibson, A. M. (2012). Methodology in Business Ethics Research: A Review and Critical Assessment. En Michalos, A. C., \& Poff, D. C. (Eds.), Citation classics from the Journal of Business Ethics: celebrating the first thirty years of publication (191-211). New York, NY: Springer.

Rezaee, Z. (2009). Corporate Governance and Ethics. USA: John Wiley \& Sons.

Riding, A. (2007). Vecinos distantes (Pacheco José, Trad.). México: Joaquín Mortiz y Planeta Mexicana. (Trabajo original publicado en 1984).

Rodríguez Córdoba, M. (2006). Ética Gerencial: Comportamientos éticos de los gerentes que más valoran los empleados en Colombia. Universidad EAFIT, 42(143), 41-54.

Rossouw, G. J. (2011). The ethics of corporate governance in global perspective. En Brink, A. (Ed.), Corporate governance and business ethics (327-341). New York, NY, Springer.

Salvador García, D. S. (1997). La dirección por valores. España: McGraw-Hill.

Schlegelmilch, B. B., \& Robertson, D. C. (1995). The influence of country and industry on ethical perceptions of senior executives in the U.S. and Europe. Journal of International Business Studies, 26(4), 859-881.

Silva, J. A. (2010). El Sentimiento de Inferioridad, la Pasión, la Pedantería y el Lenguaje Informal en una Empresa Restaurantera. Revista Reporte Final, 1(2), 43-52.

Sims, R. L., \& Keenan, J. P. (1999). A Cross-Cultural Comparison of Managers' Whistleblowing Tendencies. International Journal of Value Based Management, 12(2), 137-151.

Smith, N. C. (1991). The Case Study: A Vital Yet Misunderstood Research Method for Management. En Smith, N. C., \& Dainty, P. (Eds.), The Management Research Handbook (145-158). London, UK: Routledge.

Sower, V. E., Abshire, R. D., \& Shankman, N. A. (1997). A cross-cultural study of the ethical orientations of senior-level business students. Teaching Business Ethics, 1(4), 379-397. 
Stewart, E. C., \& Bennett, M. J. (1991). American Cultural Patterns. Yarmouth, MA: Intercultural Press.

Tadepalli, R., Moreno, A., \& Trevion, S. (1999). Do American and Mexican purchasing managers perceive ethical situations differently? An empirical investigation. Industrial Marketing Management, 28(4), 369380.

Trevino, L. K., Butterfield, K. D., \& McCabe, D. L. (1995, August). Contextual influences on ethics related outcomes in organizations: rethinking ethical climate and ethical culture. Paper presented at the Annual Academy of Management Meeting, Vancouver. Vancouver, BC: Academy of Management.

Triandis, H. C. (1996). The psychological measurement of cultural syndromes. American psychologist, 51(4), 407.

Triandis, H. C. (1982). Dimensions of cultural variations as parameters of organizational theories. International Studies of Management and Organization, 12(4), 139-169.

Tsakilis, J., \& Fritzsche, D. J. (1989). Business ethics: a literature review with a focus on marketing ethics. Journal of Business Ethics, 8(9), 695-743.

Tsalikis, J., Seaton, B., \& Shepherd, P. L. (2014). Business Ethics Index: Latin America. Journal of Business Ethics, 119(2), 209-218.

Vargas-Hernández, G., Leon-Arias, A., Valdez-Zepeda, A. \& Castillo-Giron, V. (2014). Strategic internationalization of Mexican emerging multinationals. Journal of Technology Management and Technopreneurship, 1(1), 37-69.

Villarreal, M. A. (2012). Mexico's Free Trade Agreements. (CRS Report for Congress). Washington, D.C.: Congressional Research Service.

Vizcarra, F. N. (2004). Filosofía, ética, moral y valores. México: THOMSON.

Vogel, D. (1997). Trading Up: Consumer and Environmental Regulation in a Global Economy. Cambridge, MA: Harvard University Press.

Volkema, R. J. (1998). A comparison of perceptions of ethical negotiation behavior in Mexico and the United States. International Journal of Conflict Management, 9(3), 218-233.

Weaver, G. R. (1993). Corporate codes of ethics: purpose, process and content issues. Business Society, 32(1), 44-58.

Weaver, G. R., Trevino, L. K., \& Cochran, P. L. (1999). Corporate ethics programs as control systems: influences of executive commitment and 
environmental factors. Academy of Management Journal, 42(1), 4157.

Weber, J. (1990). Managers' moral reasoning: assessing their responses to three moral dilemmas. Human Relations, 43(7), 687-702.

Windsor, D., \& Getz, K. A. (1999). Regional market integration and the development of global norms for enterprise conduct: The case of international bribery. Business \& Society, 38(4), 415-49.

Yin, R. (1989). Case study research: design and methods. Newbury Park, CA: Sage Publications. 





\section{Economía, Organización y Ciencias Sociales 3 encias}

